\title{
A Multicenter Study of Physician Mindfulness and Health Care Quality
}

\author{
Mary Catherine Beach, $M D, M P H^{1}$ \\ Debra Roter, DrPH ${ }^{1}$ \\ P. Todd Kortbuis, MD, MPH \\ Ronald M. Epstein, MD \\ Victoria Sharp, $M D^{4}$ \\ Neda Ratanawongsa, MD, MPH \\ Jonathon Cobn, $M D^{6}$ \\ Susan Eggly, $P b D^{6}$ \\ Andrea Sankar, $P b D^{6}$ \\ Richard D. Moore, MD, MHS
}

Somnath Saba, MD, MPH ${ }^{2,7}$

'Johns Hopkins University, Baltimore,

Maryland

${ }^{2}$ Oregon Health Science University, Portland, Oregon

${ }^{3}$ University of Rochester, Rochester, New York

${ }^{4}$ St Luke's-Roosevelt Medical Center, New York, New York

${ }^{5}$ University of California, San Francisco, California

${ }^{6}$ Wayne State University, Detroit, Michigan

${ }^{7}$ Portland VA Medical Center, Portland,

Oregon

Conflicts of interest: The authors report none.

\section{CORRESPONDING AUTHOR}

Mary Catherine Beach, MD, MPH

Room 2-511

Division of General Internal Medicine

Johns Hopkins University

2024 East Monument St

Baltimore, MD 21287

mcbeach@jhmi.edu

\begin{abstract}
PURPOSE Mindfulness (ie, purposeful and nonjudgmental attentiveness to one's own experience, thoughts, and feelings) is associated with physician well-being. We sought to assess whether clinician self-rated mindfulness is associated with the quality of patient care.
\end{abstract}

METHODS We conducted an observational study of 45 clinicians (34 physicians, 8 nurse practitioners, and 3 physician assistants) caring for patients infected with the human immunodeficiency virus (HIV) who completed the Mindful Attention Awareness Scale and 437 HIV-infected patients at 4 HIV specialty clinic sites across the United States. We measured patient-clinician communication quality with audio-recorded encounters coded using the Roter Interaction Analysis System (RIAS) and patient ratings of care.

RESULTS In adjusted analyses comparing clinicians with highest and lowest tertile mindfulness scores, patient visits with high-mindfulness clinicians were more likely to be characterized by a patient-centered pattern of communication (adjusted odds ratio of a patient-centered visit was $4.14 ; 95 \% \mathrm{Cl}, 1.58-10.86$ ), in which both patients and clinicians engaged in more rapport building and discussion of psychosocial issues. Clinicians with high-mindfulness scores also displayed more positive emotional tone with patients (adjusted $\beta=1.17 ; 95 \% \mathrm{Cl}, 0.46$ 1.9). Patients were more likely to give high ratings on clinician communication (adjusted prevalence ratio $[\mathrm{APR}]=1.48 ; 95 \% \mathrm{Cl}, 1.17-1.86)$ and to report high overall satisfaction (APR $=1.45 ; 95 \mathrm{Cl}, 1.15-1.84)$ with high-mindfulness clinicians. There was no association between clinician mindfulness and the amount of conversation about biomedical issues.

CONCLUSIONS Clinicians rating themselves as more mindful engage in more patient-centered communication and have more satisfied patients. Interventions should determine whether improving clinician mindfulness can also improve patient health outcomes.

Ann Fam Med 2013;421-428. doi:10.1370/afm.1507.

\section{INTRODUCTION}

M indfulness refers to a person's tendency to remain "purposefully and nonjudgmentally attentive to their own experience, thoughts and feelings."1 Mindfulness has gained popularity as a medical treatment for patients, primarily through mindfulness-based stress reduction (MBSR), with beneficial effects shown for pain, psoriasis, and depression, and with biochemical evidence of changes in immune function. ${ }^{2,3}$ Less attention has focused on the potential benefits of mindfulness among physicians and other health professionals. During the past decade, it has been recommended that physicians enhance their own capacities for mindfulness when practicing medicine and interacting with patients. ${ }^{1,4-7}$ Mindfulness is likely to have numerous personal benefits to practicing clinicians. Several studies have shown that MBSR reduces psychological distress or improves the well-being of nurses and physicians in training,${ }^{8-12}$ and a recent study found that a program teaching mindful communication reduces burnout, as well as improves self-reported well- 
being, psychosocial orientation, and empathy among practicing physicians. ${ }^{13}$

In addition to improving the personal well-being of health professionals, a theoretical potential of mindfulness to improve the quality of care delivered to patients has been described. Epstein writes of mindful practice: "This critical self-reflection enables physicians to listen attentively to patients' distress, recognize their own errors, refine their technical skills, make evidencebased decisions, and clarify their values so they can act with compassion, technical competence, presence, and insight."1 In particular, by enabling physicians to be more attentive to patients and their needs, a mindful orientation holds promise for making clinical encounters more patient centered and for enhancing patientclinician communication.

Despite the theoretical benefits of mindfulness to the patient-clinician relationship and to patients' experiences and outcomes, these associations have not been empirically studied. The purpose of this study was to assess the associations of clinicians' self-reported mindfulness with the patient-centeredness of clinical encounters, patient and clinician communication behaviors, and patients' evaluations of their care. We hypothesized that clinician mindfulness would be associated with higher quality interpersonal care.

\section{METHODS}

We conducted a cross-sectional analysis of data from the Enhancing Communication and HIV Outcomes (ECHO) Study. ${ }^{14,15}$ Study participants were patients infected with the human immunodeficiency virus (HIV) and their clinicians at 4 HIV care sites in the United States (Baltimore, Detroit, New York, and Portland). The study received institutional review board approval from each of the 4 sites; both patients and clinicians gave written informed consent. Clinicians who agreed to participate completed a baseline questionnaire. Research assistants then enrolled a convenience sample of 10 patients per clinician, placing a digital audio-recording device in the examination room to record the patient-clinician encounter. After the encounter, patients completed an interview with trained research assistants that assessed demographic, social, and behavioral characteristics, as well as patient evaluations of care.

\section{Main Measures}

\section{Clinician Mindfulness}

Our independent variable was clinician self-rated mindfulness, as measured on the baseline questionnaire by the previously validated Mindful Attention Awareness Scale (MAAS). ${ }^{16-19}$ The MAAS contains 14 items, such as, "I tend to walk quickly to where I am going without paying attention to what I experience along the way," "I find myself listening to someone with one ear, doing something else at the same time, " and "I forget a person's name almost as soon as I've been told it for the first time."16 Possible responses are on a 6-point Likert scale anchored between almost always and almost never. The total score is an average of the 14 items; higher scores indicate more mindfulness.

\section{Audio-Recorded Measures of Patient and Clinician Communication}

Audiotapes were analyzed using the Roter Interaction Analysis System (RIAS), a widely used coding system with well-documented reliability and predictive validity in assessing patient and clinician communication behaviors during medical encounters. ${ }^{20-24}$ RIAS analysts assign 1 of 37 categories to each complete thought expressed by the patient or clinician. These categories can be combined to reflect broad types of exchange, such as rapport building (talk oriented toward enhancing the patient-clinician relationship), biomedical talk (oriented toward the patients' illness and therapy), and psychosocial/lifestyle talk (oriented toward the patients' experience and life situation).

RIAS codes are used to construct a summary measure of patient-centeredness as a ratio of patientcentered categories of talk (all talk about psychosocial or lifestyle-related issues, physicians' information giving about biomedical topics, all patients' questions, all physicians' emotionally focused talk, and partnership talk) divided by physician-centered categories of talk (physicians' biomedical question asking, physicians' directive statements, and patients' biomedical information giving). ${ }^{14,15,25-28} \mathrm{~A}$ value greater than 1 denotes a more patient-centered and a value less than 1 a more doctor-centered encounter.

In addition to providing information on what was said in an encounter, the RIAS also provides global ratings of how the words were said. Emotional tone scores are calculated by summing coders' subjective ratings for patients and physicians (separately). RIAS analysts additionally recorded for each encounter the total duration of the recorded visit (visit length) and the ratio of clinician-to-patient talk during the visit (verbal dominance). All RIAS coding for this study was done by 2 women.

\section{Patient Evaluations of Care}

Patient-reported dependent variables in our analysis included (1) patients' perceptions of clinician communication, and (2) patients' overall satisfaction, derived from postencounter patient interviews. Patients rated clinician communication behaviors using the Interper- 
sonal Processes of Care Instrument's general communication subscale, which consists of 21 items. ${ }^{26}$ Possible responses were on a 5 -point scale between never and always. We measured overall satisfaction with the question, "Overall, how would you rate the quality of medical care you have received in the past 6 months?" Possible responses were on a 5 -point scale ranging between poor and excellent.

\section{Covariates}

Patient interviews also elicited the patients' sociodemographic information (age, sex, employment, education, drug use, and the single racial/ethnic group with which patients identified themselves). Medical records provided data on patients' most recent CD 4 lymphocyte counts. Clinician baseline questionnaires provided selfreported basic demographic information including age, sex, and primary racial/ethnic group.

\section{Analysis}

We used descriptive statistics to explore and describe the characteristics of our study sample. We examined the distribution, means, and internal consistencies of the mindfulness scale. Based on the nonnormal distribution of scores, we divided our mindfulness variable into low, medium, and high tertiles to account for the skewed distribution while still allowing the examination of graded associations. We then performed $t$ tests for continuous variables and $\chi^{2}$ tests for categorical variables to test for differences in patient and clinician characteristics (covariates) by clinician mindfulness.

Audiotapes from 1 of our 4 study sites included the patients' interactions with more than 1 clinician (a nurse or nurse practitioner in addition to the primary HIV clinician). For that site, it was impossible to distinguish which RIAS communication behaviors emanated from interaction with the primary HIV clinician whose mindfulness we had assessed. We therefore restricted analyses of audio-recorded communication behaviors to data obtained from the other 3 sites.

We categorized patient-centered visits vs physiciancentered visits based on whether the RIAS patientcenteredness ratio for the visit was greater than or equal to 1 or less than 1 , respectively. We used logistic regression to examine the association of clinician mindfulness with patient-centered visits. We used linear regression to compare patient and clinician communication behaviors by tertiles of clinician mindfulness. We examined several communication behaviors: rapport building, psychosocial talk, biomedical talk, and emotional tone.

Based on the positive skew in the distribution of the 2 patient evaluation variables, we dichotomized patient evaluations of communication quality (at the median score) and overall satisfaction (excellent vs all other responses). We used logistic regression to compare patient evaluations of clinician communication and patient satisfaction by clinician mindfulness tertiles. Data for these analyses came from all 4 sites.

In both bivariate and multivariate analyses, we adjusted for site and accounted for nesting of patients within clinicians using generalized estimating equations. We conducted multivariate analyses in 2 steps. In the first, we adjusted for patient and clinician age, sex, and race/ethnicity, as well as any other characteristics found to be associated with clinician mindfulness in bivariate analyses at $P<.20$. In the second step, we added visit length to each model. Adding visit length was particularly important for analyses in which our dependent variable represented counts of specific communication behaviors, because longer visits afford the opportunity for more talk by both patients and clinicians. All analyses were conducted using Stata/SE 9.0 (StataCorp LP).

\section{RESULTS}

\section{Study Sample}

There were 55 clinicians eligible for the study, and 45 (82\%) agreed to participate. We identified 617 eligible patients. Clinicians refused to allow 18 patients to be approached for the study (12 because the clinician felt too rushed, 5 because the patient was too sick, and 1 because the patient was coming for laboratory results only and not a complete visit). Of the remaining 599 patients, 437 (73\%) agreed to participate and completed all study procedures. Of the 162 patients who declined to enroll in the study, the most common reasons were that they did not have time to complete the interview $(n=106)$, were not feeling well $(n=22)$, or were no interested in studies $(\mathrm{n}=13)$.

Mindfulness scores among clinicians ranged from 2.57 to 5.93 (possible range $=1-6$ ) with a mean of 4.33. The scale had good internal consistency (Cronbach's $\alpha=.90$ ). The mean score in the low tertile was 3.53 , in the middle tertile 4.31 , and in the high tertile 5.17. Patient and clinician characteristics are displayed in Table 1. Clinician mindfulness was associated with such characteristics of his or her patient panel as patient race/ethnicity, but not with patient age, sex, education, active drug use, or CD4 lymphocyte count. Clinician mindfulness was not associated with clinician age or training background, but was associated with clinician sex and race, in that female clinicians were more likely to be in the highest mindfulness tertile and nonwhite, non-Asian clinicians were also more likely to rate themselves as high on the mindfulness scale. 


\section{Association of Clinician Mindfulness With Observed Communication Behaviors}

The overall intercoder reliability, calculated on a random sample of 41 audiotapes, across categories for patient and clinician behaviors was 0.71-0.95. In both unadjusted and adjusted analyses, higher clinician mindfulness was associated with higher odds of having a patient-centered visit (Table 2). There was some evidence of a graded association, with the odds of a patient-centered visit increasing as mindfulness increased, but only clinicians in the high tertile compared with the low tertile of mindfulness were significantly more likely to engage in patient-centered visits.

Associations of clinician mindfulness with specific clinician and patient communication behaviors are shown in Table 3. In encounters with clinicians in the high compared with the low tertile of mindfulness, both patients and clinicians engaged in substantially more rapport building and psychosocial talk. On average, clinicians with high compared with low self-rated mindfulness made 30 more statements per visit categorized as rapport building (95\% CI, 5-55), and 16 more statements related to psychosocial issues (95\% CI, 3-29). In visits with high-mindfulness compared with low-mindfulness clinicians, patients made 40 more rapport-building statements $(95 \%$ CI, 18-63) and 46 more statements about psychosocial issues (95\% CI, 20-73) per visit. Clinicians' affect, or emotional tone, during the encounter was more positive as mindfulness increased Patients' emotional tone was not significantly associated with clinician mindfulness, and we found no association between clinician mindfulness and the amount of biomedical talk during the visit. When comparing communication in the high-mindfulness with communication in the mediummindfulness categories, we also found differences only in patient rapport-building and psychosocial talk, with no statistically significant differences comparing high- with medium-mindfulness categories in the overall communication measures or in any of the clinician behaviors.

\section{Effect of Visit Length}

The average visit among HIVinfected patients and their clinicians lasted about $22 \mathrm{~min}$ utes (Table 3). After adjusting for study site and patient and clinician characteristics, highmindfulness clinicians spent on 
Table 3. Observed Patient-Clinician Communication, by Clinicians' Self-Rated Mindfulness

\begin{tabular}{|c|c|c|c|c|c|c|c|}
\hline \multirow[b]{3}{*}{ Measure } & \multirow{2}{*}{\multicolumn{3}{|c|}{$\begin{array}{c}\text { Clinician Mindfulness Tertile } \\
\text { Mean No. (SD) }\end{array}$}} & \multicolumn{4}{|c|}{$\beta$ Coefficient $(95 \% \mathrm{Cl})$} \\
\hline & & & & \multicolumn{2}{|c|}{ Adjusted for Covariates ${ }^{b}$} & \multicolumn{2}{|c|}{$\begin{array}{c}\text { Adjusted for Covariates } \\
+ \text { Visit Length }\end{array}$} \\
\hline & $\begin{array}{c}\text { Low } \\
(n=116)\end{array}$ & $\begin{array}{c}\text { Middle } \\
(n=127) \\
\end{array}$ & $\begin{array}{c}\text { High } \\
(\mathrm{n}=119)\end{array}$ & $\begin{array}{l}\text { Middle } \\
\text { vs Low }\end{array}$ & High vs Low & $\begin{array}{l}\text { Middle } \\
\text { vs Low }\end{array}$ & High vs Low \\
\hline \multicolumn{8}{|l|}{ Overall measures } \\
\hline $\begin{array}{l}\text { Visit length, } \\
\text { minutes }\end{array}$ & $22.7(9.0)$ & $22.2(8.9)$ & $22.5(10.5)$ & $\begin{array}{c}2.2 \\
(-1.9 \text { to } 6.3)\end{array}$ & $\begin{array}{c}5.8 \\
(0.9 \text { to } 10.8)\end{array}$ & - & - \\
\hline Verbal dominance & $1.36(0.6)$ & $1.49(0.5)$ & $1.24(0.4)$ & $\begin{array}{c}0.12 \\
(-0.10 \text { to } 0.34)\end{array}$ & $\begin{array}{l}-0.09 \\
(-0.34 \text { to } 0.15)\end{array}$ & $\begin{array}{c}0.12 \\
(-0.12 \text { to } 0.37)\end{array}$ & $\begin{array}{c}-0.15 \\
(-0.45 \text { to } 0.15)\end{array}$ \\
\hline \multicolumn{8}{|l|}{ Clinician behaviors } \\
\hline $\begin{array}{l}\text { Rapport-building } \\
\text { talk }\end{array}$ & $80(37)$ & $87(38)$ & $89(44)^{c}$ & $17(-3$ to 38$)$ & 30 (5 to 55$)$ & 12 (-5 to 29$)$ & 15 (-5 to 36$)$ \\
\hline Psychosocial talk & $18(18)$ & $23(27)$ & $27(29)^{c}$ & 5 (-6 to 16$)$ & 16 (3 to 29$)$ & $3(-8$ to 12$)$ & $9(-3$ to 21$)$ \\
\hline Biomedical talk & $120(63)$ & $135(71)$ & $111(66)$ & $27(-1$ to 56$)$ & $17(-17$ to 51$)$ & $16(-8$ to 40$)$ & $-12(-42$ to 17$)$ \\
\hline Emotional tone & $11.6(1.7)$ & $11.8(1.7)$ & $11.8(1.8)$ & $\begin{array}{c}0.69 \\
(0.11 \text { to } 1.3)\end{array}$ & $\begin{array}{c}1.17 \\
(0.46 \text { to } 1.9)\end{array}$ & $\begin{array}{c}0.60 \\
(0.04 \text { to } 1.6)\end{array}$ & $\begin{array}{c}0.92 \\
(0.22 \text { to } 1.6)\end{array}$ \\
\hline \multicolumn{8}{|l|}{ Patient behaviors } \\
\hline $\begin{array}{l}\text { Rapport-building } \\
\text { talk }\end{array}$ & $95(48)$ & $97(47)$ & $107(59)^{d}$ & $14(-4$ to 33$)$ & 40 (18 to 63$)$ & $6(-7$ to 19$)$ & 19 (3 to 35$)$ \\
\hline Psychosocial talk & $52(47)$ & $62(63)$ & $78(55)^{d}$ & 13 (-9 to 34$)$ & 46 (20 to 73$)$ & $6(-14$ to 25$)$ & 28 (4 to 52 ) \\
\hline Biomedical talk & $94(56)$ & $91(52)$ & $96(65)$ & 8 (-14 to 29$)$ & $23(-4$ to 50$)$ & $0(-16$ to 16$)$ & 2 (-18 to 22$)$ \\
\hline Emotional tone & $21.1(1.8)$ & $21.0(2.0)$ & $21.3(1.6)$ & $\begin{array}{c}0.07 \\
(-0.53 \text { to } 0.66)\end{array}$ & $\begin{array}{c}0.62 \\
(-0.12 \text { to } 1.36)\end{array}$ & $\begin{array}{c}0.04 \\
(-0.56 \text { to } 0.64)\end{array}$ & $\begin{array}{c}0.53 \\
(-0.22 \text { to } 1.29)\end{array}$ \\
\hline \multicolumn{8}{|c|}{ Note: Data are from 3 sites. } \\
\hline \multicolumn{8}{|c|}{$\begin{array}{l}\text { a Visit-level data for each variable. Verbal dominance is the ratio of clinician to patient talk. Talk variables are numbers of statements. Emotional tone is sum of scaled } \\
\text { ratings by coders listening to audiotaped dialogue. } \\
\text { b Results from linear regression models using generalized estimating equations to account for clustering of patients within clinicians and adjusting for study site; patient } \\
\text { age, sex, race/ethnicity, and current drug use; and clinician age, sex, and race/ethnicity. Referent group for } \beta \text { coefficients is the low clinician mindfulness tertile. } \\
{ }^{c} P<.05 \text {. }\end{array}$} \\
\hline
\end{tabular}

average 5.8 (95\% CI, 0.9-10.8) minutes longer with their patients than did those in the lowest tier. After adjusting for visit length, the association between mindfulness and the odds of a patient-centered visit (Table 2) remained significant, as did differences in patient expression of rapport-building and psychosocial statements (Table 3). Adjusting for visit length, however, did substantially reduce differences in the amount of physician rapport-building and psychosocial talk (Table 3).

\section{Patient Evaluations of Care}

The Cronbach's $\alpha$ for the interpersonal processes of care measure of communication quality in our sample was .88. In unadjusted and adjusted analyses, patients of clinicians in the high tertile compared with the low tertile of mindfulness had greater odds of reporting high-quality communication and high overall satisfaction with care (Table 4). Neither of these associations changed after accounting for visit length.

\section{DISCUSSION}

Mindfulness among health care clinicians was associated with more patient-centered communication, pro- viding the first evidence of which we are aware that clinician mindfulness is associated with the quality of care patients receive as measured by patient-centeredness and patient satisfaction. Mindfulness among clinicians was associated with more rapport building and communication about psychosocial issues between patient and clinician, and a more positive emotional atmosphere within the clinical encounter. These findings give empirical weight to Epstein's speculation that the benefits of mindful practice extend beyond the practitioner to his or her patients; it is not only that mindful practitioners can listen attentively, but that their patients are empowered to make their voice heard in areas that matter to them. It is perhaps this reciprocal communication dynamic that drives the differences observed across levels of mindfulness and the patientcenteredness score and related categories.

How might clinicians' mindfulness affect their communication with patients? Although our study did not address this question directly, we can speculate on possible explanations. Mindfulness is defined as attentiveness, curiosity, presence, and the ability to adopt multiple perspectives simultaneously-all qualities that promote greater awareness of self and oth- 
be. Finally, we cannot determine from this cross-sectional analysis whether mindfulness training for health care clinicians will result in better clinical interactions, or whether some other characteristics of mindful physicians were responsible for the positive patient outcomes we observed.

Future research should attempt to replicate these findings by measuring mindfulness among clinicians and exploring its effects on the quality of patient care in terms of patient-centeredness, as well as considering other aspects of quality, such as safety, effectiveness, efficiency, and equity. Such research might also consider exploring potential explanatory mechanisms for such findings in terms of the quality of information gathered by the clinician, clinical decision making, patient engagement, and trust. Further, studies should test whether interventions to improve the mindfulness of practicing clinicians affect patient satisfaction and other aspects of quality.

Mindfulness may be an important pathway to a more humanistic, effective, and satisfying practice of medicine. The highly reciprocal influence of patients and clinicians on one another is in itself a powerful and positive medical tool-perhaps in some situations more powerful than other interventions that can be offered to patients. In an era in which many physicians suffer professional burnout, mindful practice may be the way in which physicians not only heal themselves, but heal their patients as well.

\section{To read or post commentaries in response to this article, see it online at http://www.annfammed.org/content/11/5/421.}

Key words: patient-physician relations; patient-physician communication; mindfulness; HIV; acquired immunodeficiency syndrome

Submitted September 9, 2011; submitted, revised, November 29, 2012; accepted December 27, 2012.

Funding support: This research was supported by a contract from the Health Resources Service Administration and the Agency for Healthcare Research and Quality (AHRQ 290-01-0012). In addition, Dr Korthuis was supported by the National Institute of Drug Abuse (K23 DA019809), Dr Saha was supported by the Department of Veterans Affairs, Dr Beach was supported by the Agency for Healthcare Research and Quality (K08 HS013903-05), and both Drs Beach and Saha were supported by Robert Wood Johnson Generalist Physician Faculty Scholars Awards.

Disclaimer: None of the funders had a role in the design and conduct of this analysis, nor was it subject to their final approval.

Previous presentations: The results relating to mindfulness were presented in part at the International Conference on Communication in Healthcare (Oslo, Norway, September 2008) and the Society of General Internal Medicine's Annual National Meeting (Miami, Florida, May 2009).

\section{References}

1. Epstein RM. Mindful practice. JAMA. 1999;282(9):833-839.

2. Ludwig DS, Kabat-Zinn J. Mindfulness in medicine. JAMA. 2008; 300(11):1350-1352.
3. Segal Z, Williams J, Teasdale J. Mindfulness-based Cognitive Therapy for Depression: A New Approach to Preventing Relapse. New York, NY: The Guilford Press; 2002.

4. Connelly JE. Narrative possibilities: using mindfulness in clinical practice. Perspect Biol Med. 2005;48(1):84-94.

5. Epstein RM, Siegel DJ, Silberman J. Self-monitoring in clinical practice: a challenge for medical educators. J Contin Educ Health Prof. 2008;28(1):5-13.

6. Lovas JG, Lovas DA, Lovas PM. Mindfulness and professionalism in dentistry. J Dent Educ. 2008;72(9):998-1009.

7. Shapiro SL, Schwartz GE. Intentional systemic mindfulness: an integrative model for self-regulation and health. Adv Mind Body Med. 2000;16(2):128-134.

8. Beddoe AE, Murphy SO. Does mindfulness decrease stress and foster empathy among nursing students? J Nurs Educ. 2004;43(7): 305-312.

9. Hassed C, de Lisle S, Sullivan G, Pier C. Enhancing the health of medical students: outcomes of an integrated mindfulness and lifestyle program. Adv Health Sci Educ Theory Pract. 2009;14(3):387-398.

10. Rosenzweig S, Reibel DK, Greeson JM, Brainard GC, Hojat M. Mindfulness-based stress reduction lowers psychological distress in medical students. Teach Learn Med. 2003;15(2):88-92.

11. Shapiro SL, Schwartz GE, Bonner G. Effects of mindfulness-based stress reduction on medical and premedical students. J Behav Med. 1998;21(6):581-599.

12. Ospina-Kammerer V, Figley CR. An evaluation of the Respiratory One Method (ROM) in reducing emotional exhaustion among family physician residents. Int J Emerg Ment Health. 2003;5(1):29-32.

13. Krasner MS, Epstein RM, Beckman H, et al. Association of an educational program in mindful communication with burnout, empathy, and attitudes among primary care physicians. JAMA. 2009;302 (12):1284-1293.

14. Beach MC, Saha S, Korthuis PT, et al. Patient-provider communication differs for black compared to white HIV-infected patients. AIDS Behav. 2011;15(4):805-811.

15. Beach MC, Saha S, Korthuis PT, et al. Differences in patient-provider communication for Hispanic compared to non-Hispanic white patients in HIV care. J Gen Intern Med. 2010;25(7):682-687.

16. Brown KW, Ryan RM. The benefits of being present: mindfulness and its role in psychological well-being. J Pers Soc Psychol. 2003; 84(4):822-848.

17. Carlson LE, Brown KW. Validation of the Mindful Attention Awareness Scale in a cancer population. J Psychosom Res. 2005;58(1):29-33.

18. Garland SN, Tamagawa R, Todd SC, Speca M, Carlson LE. Increased mindfulness is related to improved stress and mood following participation in a mindfulness-based stress reduction program in individuals with cancer. Integr Cancer Ther. 2013;12(1):31-40.

19. Schütze R, Rees C, Preece M, Schütze $M$. Low mindfulness predicts pain catastrophizing in a fear-avoidance model of chronic pain. Pain. 2010;148(1):120-127.

20. Bertakis KD, Roter D, Putnam SM. The relationship of physician medical interview style to patient satisfaction. J Fam Pract. 1991; 32(2):175-181.

21. Levinson W, Roter DL, Mullooly JP, Dull VT, Frankel RM. Physicianpatient communication. The relationship with malpractice claims among primary care physicians and surgeons. JAMA. 1997;277(7): 553-559.

22. Roter DL. Patient participation in the patient-provider interaction: the effects of patient question asking on the quality of interaction, satisfaction and compliance. Health Educ Monogr. 1977;5(4):281-315.

23. Wissow LS, Roter D, Bauman LJ, et al. Patient-provider communication during the emergency department care of children with asthma. The National Cooperative Inner-City Asthma Study, National Institute of Allergy and Infectious Diseases, NIH, Bethesda, MD. Med Care. 1998;36(10):1439-1450. 
24. Roter DL, Hall JA, Katz NR. Relations between physicians' behaviors and analogue patients' satisfaction, recall, and impressions. Med Care. 1987;25(5):437-451.

25. Roter DL, Larson SM, Beach MC, Cooper LA. Interactive and evaluative correlates of dialogue sequence: a simulation study applying the RIAS to turn taking structures. Patient Educ Couns. 2008;71(1):26-33.

26. Stewart AL, Napoles-Springer A, Perez-Stable EJ. Interpersonal processes of care in diverse populations. Milbank Q. 1999;77(3): 305-339, 274

27. Mead N, Bower P. Measuring patient-centredness: a comparison of three observation-based instruments. Patient Educ Couns. 2000;39(1):71-80.

28. Cooper LA, Roter DL, Johnson RL, Ford DE, Steinwachs DM, Powe NR. Patient-centered communication, ratings of care, and concordance of patient and physician race. Ann Intern Med. 2003;139(11): 907-915.

29. Mishler E. The Discourse of Medicine: Dialectics of Medical Interviews. Norwood, NJ: Ablex; 1983.

30. Schneider J, Kaplan SH, Greenfield S, Li W, Wilson IB. Better physician-patient relationships are associated with higher reported adherence to antiretroviral therapy in patients with HIV infection. J Gen Intern Med. 2004;19(11):1096-1103.

31. Beach MC, Keruly J, Moore RD. Is the quality of the patient-provider relationship associated with better adherence and health outcomes for patients with HIV? J Gen Intern Med. 2006;21(6):661-665.
32. Musa D, Schulz R, Harris R, Silverman M, Thomas SB. Trust in the health care system and the use of preventive health services by older black and white adults. Am J Public Health. 2009;99(7):1293-1299.

33. Baer RA, Smith GT, Hopkins J, Krietemeyer J, Toney L. Using selfreport assessment methods to explore facets of mindfulness. Assessment. 2006;13(1):27-45.

34. Baer RA, Smith GT, Lykins E, et al. Construct validity of the five facet mindfulness questionnaire in meditating and nonmeditating samples. Assessment. 2008;15(3):329-342.

35. Bishop SR, Lau M, Shapiro S, et al. Mindfulness: a proposed operational definition. Clin Psychol Sci Pract. 2006;11(3):230-241.

36. Saha S, Beach MC, Cooper LA. Patient centeredness, cultural competence and healthcare quality. J Natl Med Assoc. 2008;100(11): 1275-1285.

37. Pringle $M$, Stewart-Evans $C$. Does awareness of being video recorded affect doctors' consultation behaviour? Br J Gen Pract. 1990;40(340):455-458.

38. Wolraich ML, Albanese M, Stone G, et al. Medical Communication Behavior System. An interactional analysis system for medical interactions. Med Care. 1986;24(10):891-903.

\section{Get the Annals of Family Medicine by E-mail}

Make surr you see every new issur

while it's tresh. have the rable of

contents sent to you by e-mial for

wasy atcess to artink of interest

Dont miss important research.

Request the e-mail table of contents at hetp:/lyris,aalp.orgstsubscribelannalst.

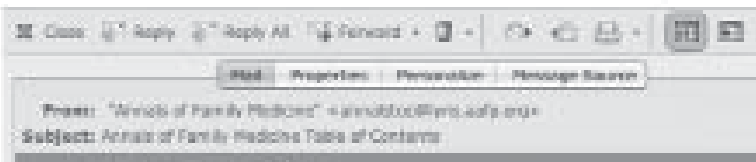

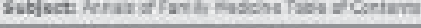

\section{IAMIII MEBDFE TNE}
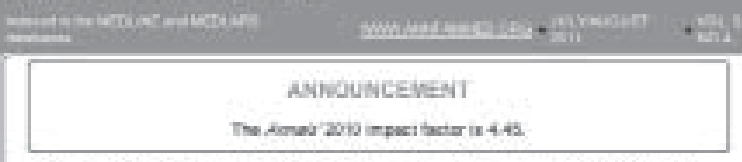

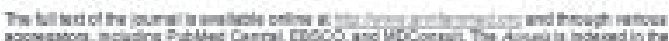

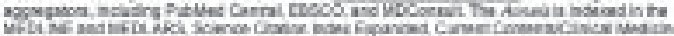

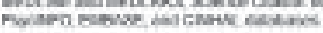

\section{EDitofins}

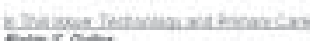

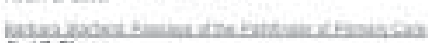

$\sin \sin$

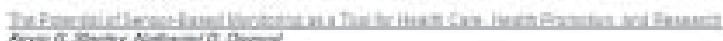

CRIGNAL RISEARCI

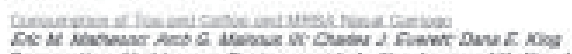

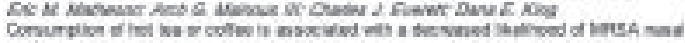
cortiven

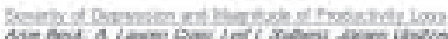

